\title{
Primary Headache Associated with Sexual Activity: Case Report
}

\author{
Uygar Utku \\ Neurology Clinic, Kahramanmaras Necip Fazil City Hospital, Kahramanmaras, Turkey
}

\author{
Key Words \\ Headache $\cdot$ Sexual activity - Differential diagnosis . \\ Indomethacin
}

\begin{abstract}
Objectives: To present a rare case of primary headache associated with sexual activity. Clinical Presentation and Intervention: A 48-year-old man presented with a severe headache during sexual intercourse, particularly at the time of orgasm. A diagnosis of type 2 primary headache associated with sexual activity was made, and he was started on indomethacin $25 \mathrm{mg}$ to be taken $30 \mathrm{~min}$ before intercourse and propranolol $40 \mathrm{mg}$ twice a day, following which he noted a dramatic improvement within in a week. Conclusions: The case highlights the importance of paying attention to the differential diagnosis. For this patient, prophylactic treatment with beta-blockers and/or preemptive therapy with indomethacin was successful. $\quad$ Copyright $\odot 2013$ S. Karger AG, Basel
\end{abstract}

\section{Introduction}

Sex-related headache is rare; its prevalence is estimated to be $1-1.6 \%$ in population-based studies $[1,2]$. The mean age of onset is in the fourth decade of life. Sex-re- lated headaches have been reported in both genders, and usually start as a dull, bilateral ache as sexual excitement increases, suddenly becoming intense at orgasm $[1,3]$. A rare sex-related headache is reported.

\section{Case Report}

A 48-year-old man presented with a severe headache occurring during sexual intercourse, particularly at the time of orgasm. He came to our clinic 2 months later. Headache was localized to the upper neck region and radiated forward to one side of the head. It started as a severe pain immediately following coitus, but was most intense at orgasm and lasted for about $10 \mathrm{~min}$. The patient described the headache as abrupt, throbbing and severe. There was no associated nausea, dizziness, phonophobia or photophobia or visual, motor or sensory disturbance. The headache was unresponsive to paracetamol and methamizol. For 3 years, he had had migraine headaches once a month that had lasted for a few hours (with a painkiller, e.g. paracetamol). He had smoked two packs of cigarettes a day for 10 years. General physical, neurological and fundoscopic examinations of the patient including blood pressure and meningeal signs were performed. Hemogram and routine biochemistry including liver and renal function tests and sedimentation ratio were normal. Brain MRI and MR artery angiography were normal. Extracranial artery ultrasonography was also normal. A diagnosis of type 2 primary headache associated with sexual activity was made. He was started on indomethacin $25 \mathrm{mg}$ taken $30 \mathrm{~min}$ before intercourse and propranolol $40 \mathrm{mg}$ twice a day, following which he noted a dramatic improvement in a week.

\section{KARGER \\ E-Mail karger@karger.com} www.karger.com/mpp

\section{(c) 2013 S. Karger AG, Basel} 1011-7571/13/0226-0588 $\$ 38.00 / 0$

Karger

0 pen access

This is an Open Access article licensed under the terms of the Creative Commons Attribution-NonCommercialNoDerivs 3.0 License (www.karger.com/OA-license), applicable to the online version of the article only. Distribution for non-commercial purposes only.
Uygar Utku, MD

Specialist in Neurology, Neurology Clinic Kahramanmaras Necip Fazil City Hospital TR-46100 Kahramanmaras (Turkey)

E-Mail utkuzar@gmail.com 


\section{Discussion}

This was a rare case of primary headache associated with sexual activity that occurs in $1-1.6 \%$ of the population $[1,2]$. This type of headache usually starts as a dull, bilateral ache during sexual intercourse, suddenly becoming intense at orgasm. Sex-related headaches generally occur without associated symptoms such as nausea, sensory or motor disturbances or unconsciousness, as in our patient.

The International Society of Headache divides sex-related headaches into two types: type 1 headaches (preorgasmic) refer to early coital cephalgia, which is usually moderate and of short duration, and type 2 headaches (orgasmic), i.e. orgasmic coital cephalgia which are abrupt, severe and last 15-20 min [4]. A diagnosis of type 2 primary headache associated with sexual activity was made for this patient. It started as a severe pain immediately following coitus, but was most intense at orgasm, and lasted about $10 \mathrm{~min}$ initially.

Factors related to the pathophysiology of sex-related headaches are mainly a trigeminovascular effect, but there is a definite muscular component and impaired cerebrovascular autoregulation [1]. A significant relationship has been found between sex-related headaches and migraine; migraine is associated more with type 2 headaches than others (25-47\%) [5]. Our patient had had a migrainous headache which lasted for a few hours with a painkiller (paracetamol) once a month for 3 years. A significant vascular or structural neurological disorder may manifest during coitus. Sex-related headaches have an association with intracranial space-occupying lesions, such as tumors, subdural hematoma, unruptured aneu- rysms, cerebral venous sinus thrombosis, carotid artery dissection and intracranial hypertension. In particular, subarachnoid hemorrhage is well known to be precipitated by coitus [5, 6]. Yeh et al. [7] found that intracranial vascular disorders were very common in patients with sex-related headaches. Sudden headache, which can be the first manifestation, should always be investigated carefully to rule out a dangerous intracranial event. Thorough neurovascular imaging is required for all patients with sex-related headaches [6-8]. Brain MRI and MR artery angiography were normal in this patient.

With regard to treatment as a preventive step, several drugs have been useful. Indomethacin ( $25-50 \mathrm{mg}$ /day) or propranolol (40-200 $\mathrm{mg} /$ day) have been reported to be effective [9]. Prophylaxis can be advised for a period of 3-6 months and then the patient should be checked for spontaneous remission. This case showed an excellent response with a treatment of indomethacin $25 \mathrm{mg} /$ day taken before intercourse and propranolol $40 \mathrm{mg}$ twice a day, following which he noted a dramatic improvement in the space of a week. Sex-related headaches are usually benign self-limiting conditions. The prognosis is good and should be explained to the patient.

\section{Conclusion}

This was a rare case of primary headache associated with sexual activity. The case highlights the importance of paying attention to the differential diagnosis. For this patient, prophylactic treatment with beta-blockers and preemptive therapy with indomethacin were successful.

\section{References}

$>1$ Frese A, Eikermann A, Frese K, et al: Headache associated with sexual activity. Demography, clinical features and comorbidity. Neurology 2003;61:796-800.

-2 Tugba T, Ucler S, Okuyucu E, et al: Features of stabbing, cough, exertional, and sexual headaches in a Turkish population of headache patients. J Clin Neurosci 2008;15:774-777.

$\checkmark 3$ Chakravarty A: Primary headaches associated with sexual activity-some observations in Indian patients. Cephalalgia 2006;26:202-207.
4 Headache Classification Subcommittee of the International Headache Society: The International Classification of Headache Disorders: 2nd edition. Cephalalgia 2004;24:9-160.

$\checkmark 5$ Pascual J, Iglesias F, Oterino A, et al: Cough, exertional and sexual headaches. An analysis of 72 benign and symptomatic cases. Neurology 1996;46:1520-1524.

6 Goldstein J: Sexual aspects of headache. How sexual function relates to headaches and their causes and treatment. Postgrad Med 2001; 109:81-84, 87-88, 92.
7 Yeh YC, Fuh JL, Chen SP, et al: Clinical features, imaging findings and outcomes of headache associated with sexual activity. Cephalalgia 2010;30:1329-1335.

$>8$ Kosma KK, Kararizou E, Markou I, et al: Headache as a first manifestation of VogtKoyanagi-Harada disease. Med Princ Pract 2008;17:253-254.

-9 Sands GH, Newman L, Lipton R: Cough, exertional, and other miscellaneous headaches. Med Clin North Am 1991;75:733-747. 